\title{
Cerebrospinal Fluid Ferritin in Patients with Central Nervous System Tumors
}

\author{
YOSHIHIRO SATO, YOUSUKE SATO, TAKASHI HAYASHI*, \\ KAZUHITO SHOJIMA* AND MASARO KAJI**
Departments of Neurology and Neurosurgery*, St. Mary's Hospital and ${ }^{* *}$ Department of Internal Medicine, Kurume University School of Medicine, Kurume, 830 Japan

Received for publication July 24, 1985

\begin{abstract}
Summary: Ferritin was measured in the cerebrospinal fluid (CSF) of nine patients with central nervous system (CNS) tumors and 11 control subjects. The mean ferritin concentration for the control group was $4.4 \mathrm{ng} / \mathrm{ml}$ with an upper limit at $9.5 \mathrm{ng} / \mathrm{ml}$. High ferritin concentrations were observed in six patients with CNS tumors, in two patients with glioblastoma multiforme and in single patients with medulloblastoma, metastatic brain tumor, CNS lymphoma or meningeal carcinomatosis. Four of the six patients had CSF seeding as revealed by a CT scan or CSF cytology. When serum and CSF values were measured simultaneously, ferritin in the CSF exceeded the serum concentrations in one of the patients with glioblastoma multiforme. In two patients, the ferritin concentrations fluctuated depending on their clinical status. These data suggest that serial determinations of ferritin in the CSF may be useful for clinical management of some CNS tumors.
\end{abstract}

Key words: ferritin - cerebrospinal fluid - central nervous system tumor glioma - lymphoma - meningeal carcinomatosis

\section{Introduction}

In recent years, biochemical markers in the cerebrospinal fluid (CSF) for central nervous system (CNS) tumors, such as carcinoembryonic antigen and $\beta$-glucuronidase in leptomeningeal carcinomatosis (Schold et al, 1980; Yap et al. 1980) and $\beta_{2}$-microglobulin in CNS leukemia and lymphoma (Mavligit et al. 1980; Sato et al. 1983), have become increasingly important both in the diagnosis and in following the course of a neoplastic CNS illness. Although it has been recognized that tumor markers, such as glutamic oxaloacetic transaminase, lactic dehydrogenase (Fleisher et al. 1958; Green et al. 1959; Jakoby and Jakoby, 1958), polyamine (Marton et al. 1974) and $\alpha$-fetoprotein (Smith et al. 1971) are present in the CSF, the clinical importance of these markers in the diagnosis of CNS tumors has not been considered.

In the present study, CSF ferritin was measured in patients with CNS tumors to determine whether it could be related to the following: (1) the type and site of the CNS tumor and (2) a prediction of clinical improvement, relapse, or response to treatment.

\section{Material and Method}

Blood serum and CSF samples were collected from patients with CNS tumors. The diagnosis of each patient is listed in Table 1. CSF was collected from 11 patients who had muscle contraction head- 
TABLE 1

List of patients with central nervous system tumors

\begin{tabular}{ccll}
\hline $\begin{array}{c}\text { Patient } \\
\text { No. }\end{array}$ & $\begin{array}{c}\text { Age and } \\
\text { Sex }\end{array}$ & \multicolumn{1}{c}{ Diagnosis } & \multicolumn{1}{c}{ Remark } \\
\hline 1 & $56, \mathrm{M}$ & Glioblastoma multiforme & CSF seeding on CT scan \\
2 & $61, \mathrm{~F}$ & Glioblastoma multiforme & \\
3 & $57, \mathrm{M}$ & Glioblastoma multiforme & \\
4 & $72, \mathrm{~F}$ & Glioblastoma multiforme & \\
5 & $15, \mathrm{M}$ & Medulloblastoma & CSF seeding on CT scan \\
6 & $69, \mathrm{M}$ & Metastatic brain tumor & Adenocarcinoma of the lung \\
7 & $80, \mathrm{~F}$ & Metastatic brain tumor & Adenocarcinoma of the lung \\
8 & $70, \mathrm{M}$ & CNS lymphoma & CSF seeding on cytology \\
9 & $64, \mathrm{~F}$ & Meningeal carcinomatosis & Adenocarcinoma of the gallbladder \\
\hline
\end{tabular}

ache (mean age of 47 years), and was used for a control. For comparison, 13 patients with aseptic meningitis (mean age of 28) were also included in the study. The CSF was obtained from the lumbar space by direct puncture. The CSF and serum samples were usually collected simultaneously. The samples were stored at $-20{ }^{\circ} \mathrm{C}$.

The ferritin concentration in the CSF or serum was determined by radioimmunoassay with commercially available 125 Ilabeled and unlabeled ferritin preparations (Spac Kit; Daiichi Radioisotope, Japan).

\section{Result}

Fig. 1 shows the differences in the CSF ferritin concentrations in the three groups of patients. In the control patients, the ferritin concentration in the CSF ranged from 2.2 to $8.6 \mathrm{ng} / \mathrm{ml}$ (mean: $4.4 \mathrm{ng} / \mathrm{ml}$; SD: $1.7 \mathrm{ng} / \mathrm{ml}$ ). The upper normal limit was $9.5 \mathrm{ng} / \mathrm{ml}$ (mean value $+3 \mathrm{SD}$ ). In the patients with aseptic meningitis, the ferritin ranged from 2.6 to $9.7 \mathrm{ng} / \mathrm{ml}$ with a mean of $5.8 \pm 2.2( \pm \mathrm{SD})$. Only one patient with aseptic meningitis had a value above the upper normal limit. Patients with CNS tumors had ferritin values ranging from 3.3 to $120 \mathrm{ng} / \mathrm{ml}$ with a mean of 25.6 $6 \pm 36.6$. Elevated CSF ferritin was ob- served in two patients with glioblastoma multiforme and in individual patients with medulloblastoma, metastatic brain tumor, CNS lymphoma and meningeal carcinoma-

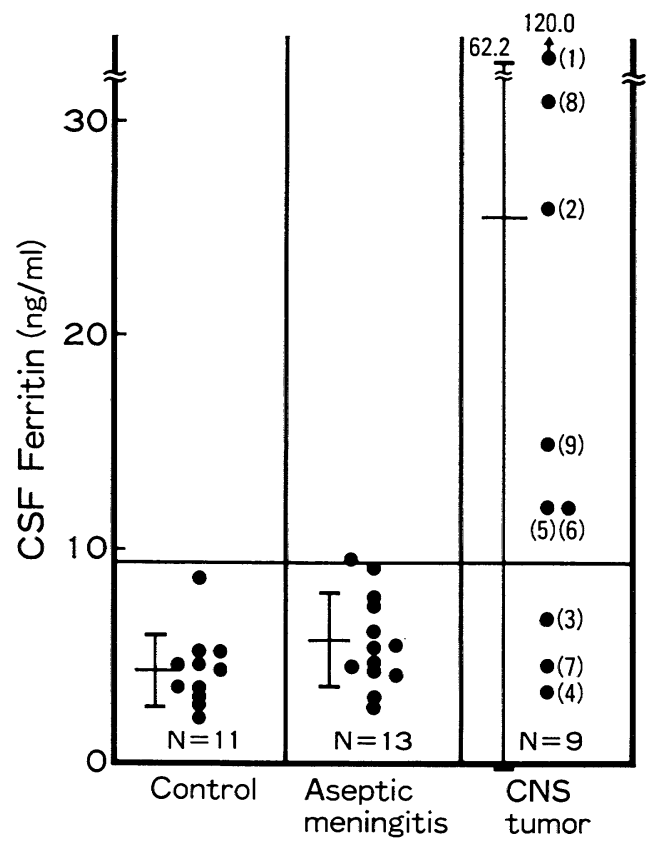

Fig. 1. Ferritin concentration in CSF of control patients, patients with aseptic meningitis and patients with CNS tumors. The line indicates the upper normal limit. The figure in parentheses is the case number corresponding to patients in Table 1. 
tosis. There was evidence of CSF seeding from the CT scan or CSF cytology in the patients with elevated CSF ferritin, except one patient who had a glioblastoma and one who had a metastatic brain tumor. Correlations were not observed between CSF ferritin and CSF cell count $(r=-0.04$, $\mathrm{N}=33$ ), or CSF ferritin and CSF protein $(\mathrm{r}=0.36, \mathrm{~N}=33)$. There was a poor relationship between serum and CSF ferritin concentrations $(\mathrm{r}=-0.03, \mathrm{~N}=24)$.

The CSF ferritin values were expressed as percentage of the corresponding serum ferritin ( $\mathrm{CSF} /$ serum ratio). As shown in Fig. 2, the CSF/serum ratio in the control subjects ranged from 1.3 to $7.2 \%$ with a

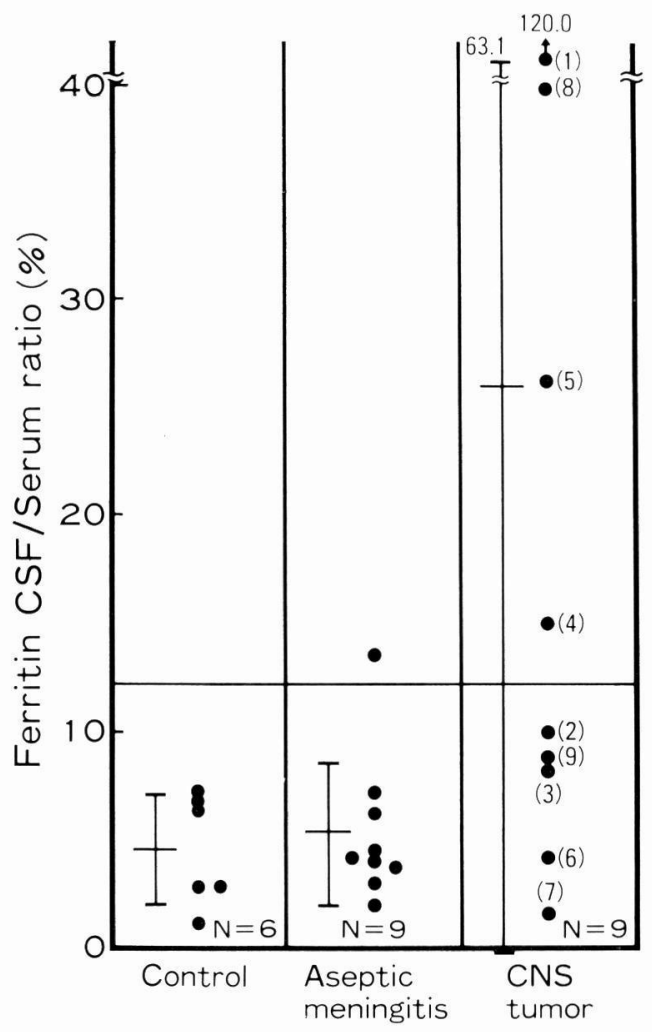

Fig. 2. $\mathrm{CSF} /$ serum ratios for ferritin in each group. The line indicates the upper normal limit. The figure in parentheses is the case number corresponding to the patients in Table 1. mean of $4.6 \pm 2.6( \pm \mathrm{SD})$. The upper normal limit was $12.2 \%$ (mean value $+3 \mathrm{SD}$ ). Elevated values of the $\mathrm{CSF} /$ serum ratio of ferritin were observed in two patients with glioblastoma multiforme and single patients with a medulloblastoma, a CNS lymphoma and aseptic meningitis. One patient with a glioblastoma had a value of $120 \%$. An other patient with a glioblastoma had a normal CSF ferritin concentration with a high ratio.

The concentrations of ferritin in the CSF were serially determined from four patients with CNS tumors (Table 2). Case 1 had a right hemiparesis, right homonymous hemianopsia and slight motor aphasia. CSF tumor cell seeding was observed with the CT scan on May 6, 1983. Although he received whole brain radiation from July 22, 1983 to October 4, he became drowsy and the hemiparesis and motor aphasia worsened. On January 7, 1984, the CT scan also indicated CSF tumor cell seeding (Fig. 3). As shown in Table 2, both

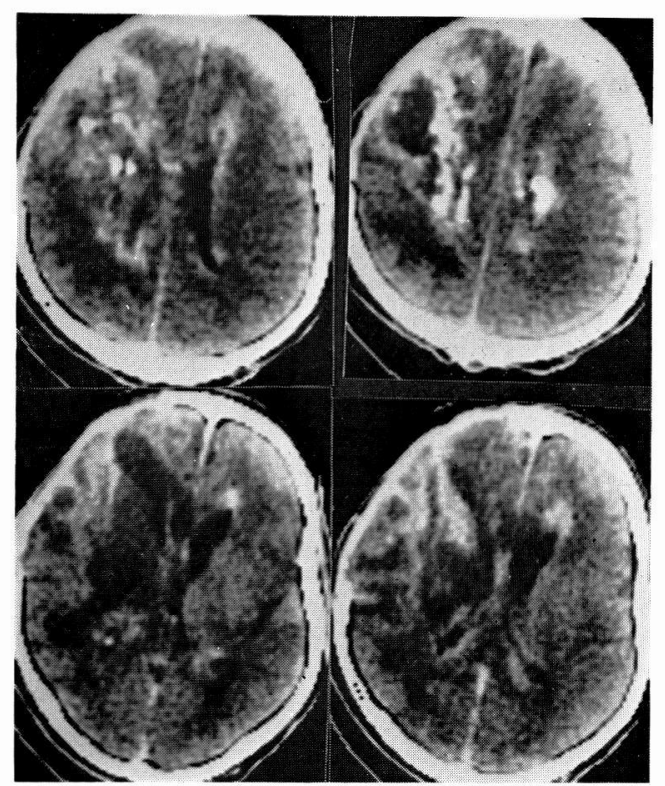

Fig. 3. A CT scan of Case 1, demonstrating ependymal-subependymal enhancement after contrast. 
TABLE 2

Serial determinations of ferritin in the cerebrospinal fluid of patients with CNS tumors

\begin{tabular}{|c|c|c|c|c|c|c|c|}
\hline \multirow{2}{*}{$\begin{array}{c}\text { Case } \\
\text { No. }\end{array}$} & \multirow[b]{2}{*}{ Date } & \multicolumn{3}{|c|}{ Ferritin } & \multicolumn{2}{|c|}{ CSF findings } & \multirow[b]{2}{*}{ Treatment } \\
\hline & & $\begin{array}{c}\mathrm{CSF} \\
(\mathrm{ng} / \mathrm{ml})\end{array}$ & $\begin{array}{l}\text { Serum } \\
(\mathrm{ng} / \mathrm{ml})\end{array}$ & $\begin{array}{l}\text { Ratio } \\
(\%)\end{array}$ & $\begin{array}{l}\text { Cell count } \\
(3 \mathrm{c} . \mathrm{mm})\end{array}$ & $\begin{array}{l}\text { Protein } \\
(\mathrm{mg} / \mathrm{dl})\end{array}$ & \\
\hline \multirow[t]{2}{*}{1} & 1983. $6 / 2$ & 16 & 37 & 43 & 0 & 41 & \multirow[t]{2}{*}{ Whole brain radiation } \\
\hline & 1984. $1 / 9$ & 120 & 100 & 120 & 19 & 120 & \\
\hline \multirow[t]{5}{*}{5} & 1983. $5 / 21$ & 12 & 46 & 26 & 1,104 & 83 & \multirow{5}{*}{$\begin{array}{l}\text { Intrathecal } \\
\text { methotrexate }\end{array}$} \\
\hline & 1983. $5 / 30$ & 11 & 33 & 33 & 491 & 52 & \\
\hline & 1983. $6 / 6$ & 20 & 50 & 40 & 49 & 48 & \\
\hline & 1983. $6 / 10$ & 16 & 77 & 21 & 379 & 62 & \\
\hline & 1983. $6 / 29$ & 14 & 36 & 39 & 860 & 100 & \\
\hline \multirow[t]{3}{*}{8} & 1983. $9 / 14$ & 31 & 78 & 40 & 275 & 510 & \multirow{3}{*}{$\begin{array}{l}\text { Intravenous } \\
\text { betamethasone }\end{array}$} \\
\hline & $1983.10 / 5$ & 24 & 180 & 13 & 95 & 96 & \\
\hline & $1983.10 / 12$ & 26 & 260 & 10 & 21 & 38 & \\
\hline \multirow[t]{4}{*}{9} & 1983. $7 / 13$ & 15 & 170 & 9 & 352 & 67 & \\
\hline & 1983. $7 / 18$ & 24 & 330 & 7 & 141 & 48 & \multirow{3}{*}{$\begin{array}{l}\text { Intrathecal } \\
\text { methotrexate }\end{array}$} \\
\hline & 1983. $7 / 22$ & 27 & 650 & 4 & - & 44 & \\
\hline & 1983. $7 / 29$ & 64 & 1,400 & 5 & 30 & 54 & \\
\hline
\end{tabular}

Case No. corresponds to Table 1. Ratio: CSF/serum ratio of ferritin

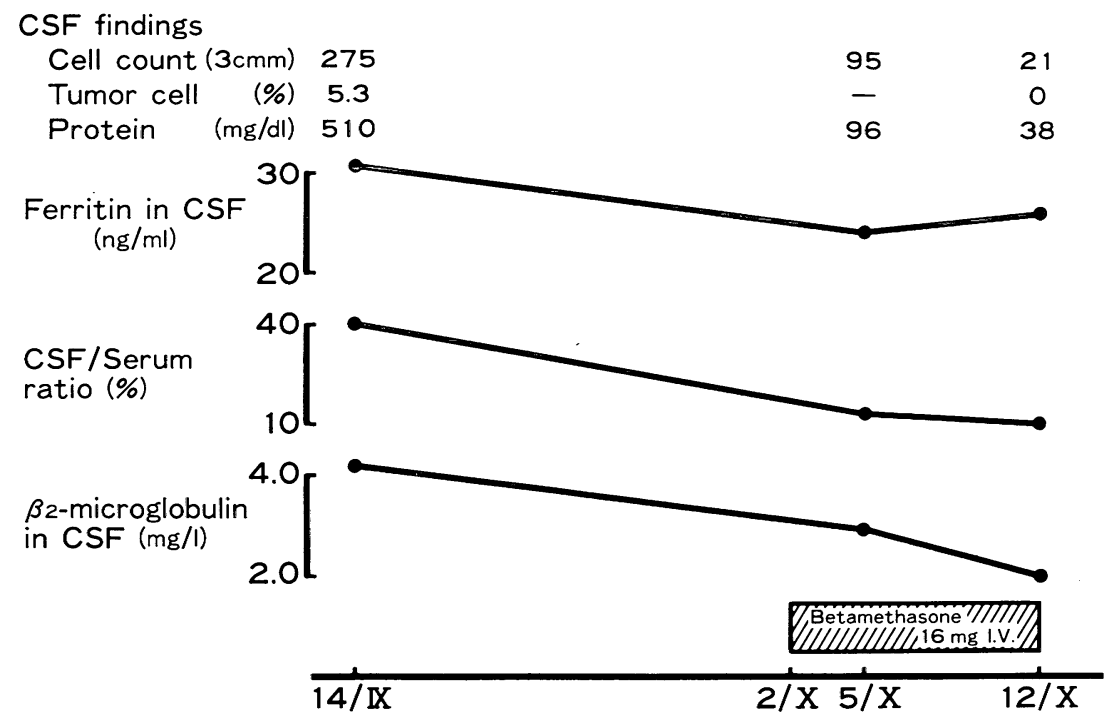

Fig. 4. The clinical course, CSF ferritin and CSF/serum ferritin ratio for Case 8. 


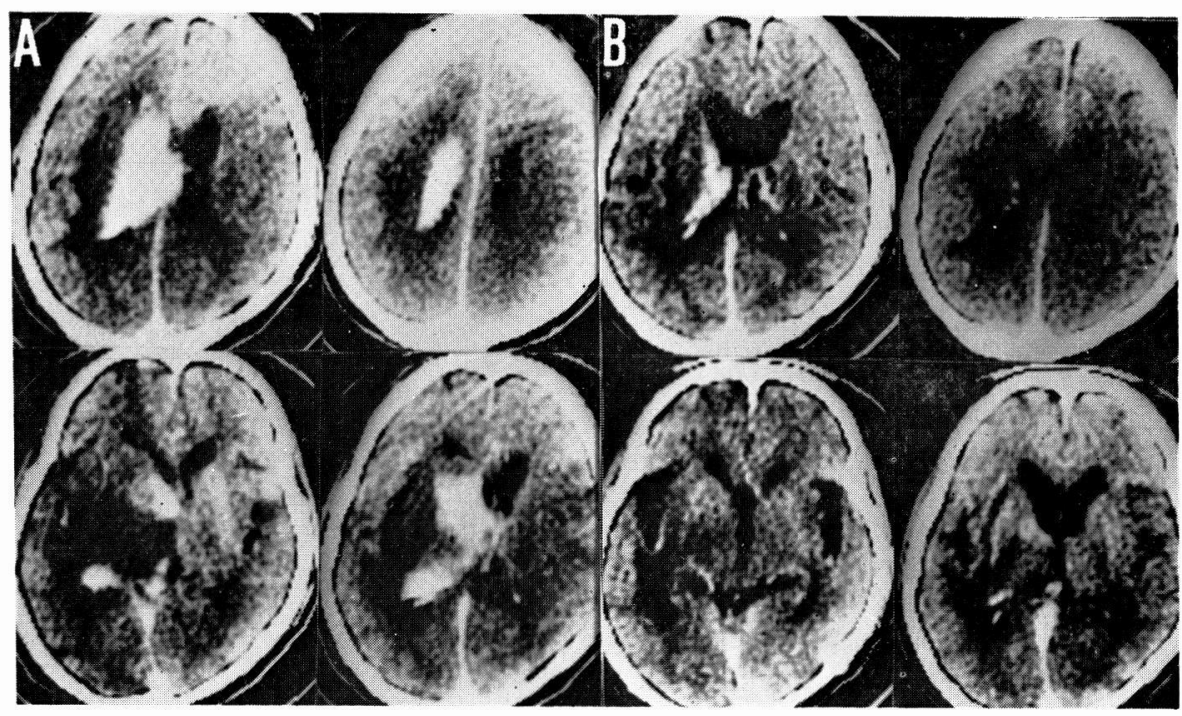

Fig. 5. Postcontrast CT scan for Case 8

(A) An enhancing mass is present in the regions of the left frontal and temporal lobes, caudate nucleus, and thalamus.

(B) The tumor was reduced in size after steroid treatment.

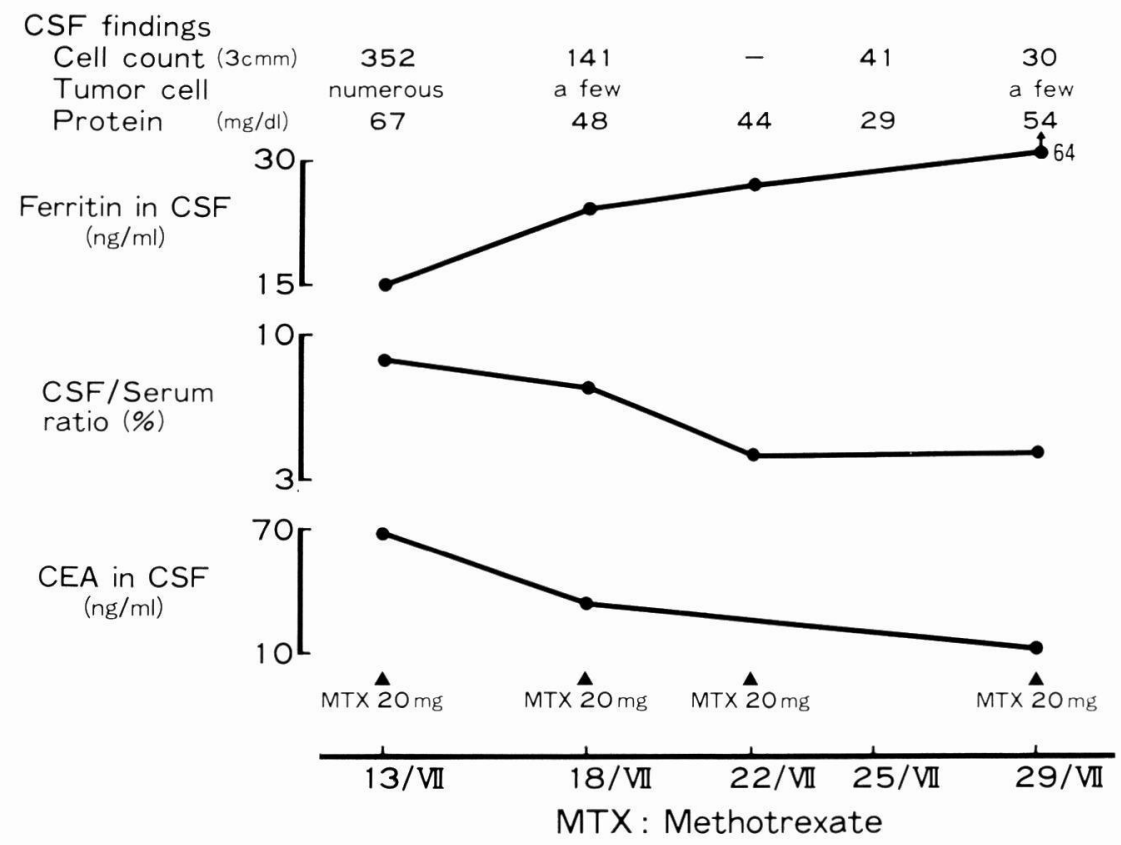

Fig. 6. The clinical course, CSF ferritin and CSF/serum ferritin ratio for Case 9 . 
$\mathrm{CSF}$ ferritin and the CSF/serum ferritin ratio increased from $16 \mathrm{ng} / \mathrm{ml}$ to $120 \mathrm{ng} / \mathrm{ml}$ and $43 \%$ to $120 \%$, respectively.

Although the CSF cell count decreased after intrathecal administration of methotrexate in case 5 , both CSF ferritin and the $\mathrm{CSF} /$ serum ferritin ratio increased.

As shown in Fig. 4, case 8 responded to intravenous administration of betamethasone with a marked improvement of CSF and CT findings (Fig. 5). There were decreases in both CSF ferritin and the $\mathrm{CSF}$ /serum ferritin ratio, as well as CSF $\beta_{2}$-microglobulin.

Although intrathecal administration of methotrexate improved the signs of meningeal irritation and the CSF cytologic findings and decreased the cell count in case 9 , the CSF ferritin was increased. The CSF/ serum ferritin ratio was decreased, as well as the carcinoembryonic antigen, in association with improvement of the meningeal illness (Fig. 6).

\section{Discussion}

Ferritin is the major iron storage protein in the body. It is found in various tissues of humans and is thought to consist of a spherical protein shell with a molecular weight of approximately 450, 000. It is composed of 24 subunits, each with various amounts of iron (Jacobs and Worwood, 1975). High serum ferritin concentrations have been found in patients with leukemia, malignant lymphoma and solid tumors such as gastric, rectal, hepatic and lung carcinomas (Hazard and Drysdale, 1977; Jones et al. 1973; Niitsu et al. 1975). This may be a reflection of increased ferritin synthesis by neoplastic tissue (White et al. 1974).

Hällgren et al. (1980) was the first investigator to report that ferritin was detectable in the CSF of healthy men. Elevations of CSF ferritin have previously been reported in CNS infections, cerebro- vascular diseases and a few cases of primary CNS tumors (Hällgren et al. 1980; Sindic et al. 1981). The results of the present study indicate that elevated levels of ferritin in the CSF were most readily found in patients with gliomas especially with CSF seeding, CNS lymphoma and meningeal carcinomatosis. Furthermore, one patient with a glioblastoma multiforme who responded poorly to radiation therapy had an increased CSF ferritin. A CNS lymphoma patient with an elevated CSF ferritin responded well to treatment and his CSF ferritin subsequently decreased.

Since the molecular weight of ferritin is large, the entry of ferritin into the CSF from the serum must be small amount. Furthermore, aseptic meningitis did not lead to an elevation of CSF ferritin, except in one patient. Therefore, it can be concluded that a disruption of the blood-brain barrier is not responsible for the elevation of ferritin in the CSF in patients with CNS tumors. As the CSF ferritin exceeded the serum concentration in the patient with glioblastoma multiforme, the elevated ferritin values in the CSF are probably due to the liberation of ferritin from neoplastic cells in the CNS. Although the CSF values of ferritin may be independent of the serum levels, the CSF ferritin must be compared to the serum value. In fact, the case with meningeal carcinomatosis had a decreased CSF/serum ratio of ferritin after improvement of the illness, in spite of an increase in CSF ferritin. This was due to the higher concentration of serum ferritin.

\section{References}

Fleisher, G. A., Wakim, K. G. and Goldstein, N. P. (1958). Glutamic oxaloacetic transaminase and lactic dehydrogenase. Mayo Clin. Proc. 32, 188-197.

Green, J. B., Oldewurtel, H. A. and Forster, F. M. (1959). Glutamic oxaloacetic transaminase and lactic dehydrogenase activities. Neurology (Minneap), 9, 540-544. 
Hällgren, R., Terent, A., Wide, L., Bergstrom, K. and BirgegArd, G. (1980). Cerebrospinal fluid ferritin in patients with cerebral infarction or bleeding. Acta Neurol. Scand. 61, 384-392.

Hazard, J. T. and Drysdale, J. W. (1977). Ferritinaemia in cancer. Nature, 265, 755-756.

JACOBS, A. and Worwood, M. (1975). Ferritin in serum. Clinical and biochemical implications. N. Engl. J. Med. 292, 951-956.

ЈАкову, R. and ЈАКову, W. (1958). Lactic dehydrogenase of cerebrospinal fluid in the differential diagnosis of cerebrovascular disease and brain tumor. J. Neurosurg. 15, 45-51.

Jones, P. A. E., Miller, F. M., Worwood, M. and JACOBS, A. (1973). Ferritinaemia in leukaemia and Hodgkin's disease. Br. J. Cancer, 27, 212217.

Marton, L. J., Heby, O. and Wilson, C.B. (1974). Increased polyamine concentrations in the cerebrospinal fluid of patients with brain tumors. Int. J. Cancer, 14, 731-735.

Mavligit, G. M., Stuckey, S. E., Cabanillas, F. F., Keating, M. J., Tourtellotte, W. W., Schold, S. C. and Freireich, E. J. (1980). Diagnosis of leukemia or lymphoma in the central nervous system by beta 2 -microglobulin determination. N. Engl. J. Med. 303, 718-722.

Nitssu, Y., Kohgo, Y., Yокота, M. and UrushiZAKI, I. (1975). Radioimmunoassay of serum ferritin in patients with malignancy. Ann. N. Y. Acad. Sci. 259, 450-452.

Sato, Y., Egami, K., Natori, H., Schoji, H. and KAJI, M. (1983). CSF $\beta_{2}$-microglobulin in the diagnosis of disseminated meningeal malignant neoplasms. Neurol. Med. (Tokyo) 18, 341345.

Schold, S. C., Wasserstrom, W. R., Fleisher, M., Schwartz, M.K. and Posner, J. B. (1980). Cerebrospinal fluid biochemical markers of central nervous system metastases. Ann. Neurol. 8, 597-604.

Sindic, C. J. M., Collet-Cassart, D., Cambiaso, C.L., Masson, P.L. and Laterre, E.C. (1981). The clinical relevance of ferritin concentration in the cerebrospinal fluid. J. Neurol. Neurosurg. Psychiatry, 44, 329-333.

Smith, J. A., Francis, T. I., Edington, G. M. and Williams, A. D. (1971). Human $\alpha$-fetoprotein in the body fluids. Br. J. Cancer, 25, 337-342.

White, G. P., Worwood, M., Parry, D. H. and JACOBS, A. (1974). Ferritin synthesis in normal and leukemic leukocytes. Nature, 250, 584585.

Yap, B. S., Yap, H. Y., Fritsche, H. A., BlumensCHEIN, G. and Bodey, G. P. (1980). CSF carcinoembryonic antigen in meningeal carcinomatosis from breast cancer. J. A. M. A. 244, 1601-1603. 